\title{
GABA Receptors Containing Rdl Subunits Mediate Fast Inhibitory Synaptic Transmission in Drosophila Neurons
}

\author{
Daewoo Lee, Hailing Su, and Diane K. O'Dowd \\ Departments of Anatomy and Neurobiology, Developmental and Cell Biology, University of California, Irvine, California 92697-1280
}

\begin{abstract}
GABAergic inhibition in Drosophila, as in other insects and mammals, is important for regulation of activity in the CNS. However, the functional properties of synaptic GABA receptors in Drosophila have not been described. Here, we report that spontaneous GABAergic postsynaptic currents (sPSCs) in cultured embryonic Drosophila neurons are mediated by picrotoxin-sensitive chloride-conducting receptors. A rapid increase in spontaneous firing in response to bath application of picrotoxin demonstrates that these GABA receptors mediate inhibition in the neuronal networks formed in culture. Many of the spontaneous GABAergic synaptic currents are sodium action potential independent [miniature IPSCs (mIPSCs)] but are regulated by external calcium levels. The large variation in mIPSC frequency, amplitude, and kinetics properties between neurons suggests heterogeneity in GABA receptor number, location, and/or subtype. A decrease in the mean mIPSC decay time constant between 2 and $5 \mathrm{~d}$, in the absence of a correlated change in rise time, demonstrates that the functional properties of the synaptic GABA receptors are regulated during maturation in vitro. Finally, neurons from the GABA receptor subunit mutant $R d l$ exhibit reduced sensitivity to picrotoxin blockade of the mIPSCs and resistance to picrotoxin-induced increases in spontaneous firing frequency. This demonstrates that $\mathrm{Rdl}$ containing GABA receptors play a direct role in mediating synaptic inhibition in Drosophila neural circuits formed in culture.
\end{abstract}

Key words: Drosophila; GABAergic synaptic transmission; GABA receptor; Rdl receptors; development; synaptic inhibition

\section{Introduction}

Fast inhibitory synaptic transmission, mediated by ionotropic GABA receptors, plays a critical role in regulating neuronal activity in the nervous system of both vertebrates and invertebrates (Mody et al., 1994; Hosie et al., 1997). GABAergic neurons and GABA receptors are found throughout the Drosophila CNS at all developmental stages (Buchner et al., 1988; Jackson et al., 1990; Harrison et al., 1996; Yusuyama et al., 2002). Although GABAergic synaptic inhibition has not been examined directly, it appears to modulate neuronal activity in Drosophila, as in other animals, on the basis of induction of convulsive behaviors, reduction in locomotor activity, and deficits in geotaxis after pharmacological disruption of GABA transporter function in the adult fly (Leal and Neckameyer, 2002). In addition, genetic deletions removing the glutamic acid decarboxylase locus or the Rdl GABA receptor locus result in embryonic lethality demonstrating that the GABAergic system is also important in early neural development in Drosophila (Kulkarni et al., 1994; Stilwell et al., 1995). The ability to combine behavioral analysis with sophisticated molecular genetics makes Drosophila an attractive model system to identify genes involved in the function and regulation of GABAergic inhibition in the developing and mature nervous system.

In all species, expression of multiple GABA receptor subunit

Received Jan. 14, 2003; revised March 11, 2003; accepted March 17, 2003.

This work was supported by National Institutes of Health Grants NS27501 and DA14960. We thank Aeran Lee, Betty Sicaeros, and Dr. A. Gopalakrishnan for technical assistance, and Dr. M. A. Smith for helpful comments on previous versions of this manuscript.

Correspondence should be addressed to Diane K. O'Dowd, Departments of Anatomy and Neurobiology, University of California, Irvine, CA 92697-1280. E-mail: dkodowd@uci.edu.

D. Lee's present address: Department of Biological Sciences, Ohio University, Athens, OH 45701.

Copyright $\odot 2003$ Society for Neuroscience $\quad$ 0270-6474/03/234625-10\$15.00/0 genes results in the formation of heteromultimeric ionotropic GABA receptors with distinct functional properties and expression patterns (Wisden and Seeburg, 1992; Vicini, 1999; Rudolph et al., 2001). Three ionotropic GABA receptor subunits (Rdl, LCCH3, and GRD) have been cloned in Drosophila (Hosie et al., 1997). Rdl, originally identified as an insecticide resistant mutant, forms picrotoxin (PTX)-sensitive, bicuculline methylchloride (BMC)-insensitive GABA-gated chloride channels when expressed in oocytes and Sf2 cells (ffrench-Constant et al., 1990, 1993a; Zhang et al., 1995). In contrast, coexpression of Rdl and LCCH3 (a $\beta$-like subunit) results in the formation of a pharmacologically distinct PTX-insensitive, BMC-sensitive channel (Zhang et al., 1995). Examination of GABA-evoked currents demonstrates that larval Drosophila neurons express receptors with Rdl homomultimer-like pharmacological properties (Zhang et al., 1995). However, differences in properties of single channels observed in Rdl-injected oocytes and larval neurons suggest that native GABA receptors are not Rdl homomultimers (Zhang et al., 1995). Because GABAergic synaptic currents in Drosophila have, to this point, eluded description, the functional properties of synaptic GABA receptors and the contribution of specific subunits are unknown.

Although electrophysiological analysis of GABAergic synaptic transmission in vivo has not yet proved tractable, we reported previously that embryonic Drosophila neurons form spontaneously active GABAergic synapses when grown in dissociated cell culture (Lee and O'Dowd, 1999). The data in this study provide the first insights into the pharmacological and biophysical properties of the receptors mediating these synaptic currents during early development. Analysis of mutant neurons demonstrates that $R d l$ encoded subunits contribute to the population of synaptic receptors. In addition, a resistance to PTX-induced increases 
in neuronal excitation in $R d l$ mutant cultures indicates that $\mathrm{Rdl}-$ containing GABA receptors mediate spontaneously active inhibitory transmission.

\section{Materials and Methods}

Cultures. Each culture was prepared from one or two midgastrula stage embryos, plated on uncoated glass coverslips and grown in a chemically defined medium (DDM1) as described previously, with the modification that hydrocortisone was omitted from the DDM1 formulation (O'Dowd, 1995). Cultures were maintained in an incubator supplied with $5 \% \mathrm{CO}_{2}$ at $23-24^{\circ} \mathrm{C}$ for up to $9 \mathrm{~d}$ in vitro (DIV). The wild-type data in this study were obtained from cultures prepared from two wild-type stocks, Canton-S and Oregon-R. There were no significant differences in the properties measured between these two strains, and, therefore, the data were pooled. The $R d l^{[M D-R R]}$ mutant strain, in an Oregon-R background, was obtained from Bloomington Stock Center (Indiana University, Bloomington, IN). This strain carries two point mutations, only one of which (A302S) is responsible for the insecticide resistance and altered picrotoxin sensitivity of the mutant channels (ffrench-Constant et al., 1993a,b). To confirm the presence of the A302S point mutation in the $R d l$ mutant neurons, we harvested total RNA from embryos and cultures at 3-4 d in vitro, both $R d l$ and wild type, and performed reverse transcription-PCR using primers flanking the mutation A302S (ffrenchConstant et al., 1993b). As expected, digestion of the PCR products with the restriction enzyme HaeII resulted in three fragments in the wild-type samples and two fragments in the $R d l$ samples of the appropriate size (data not shown). These results confirmed that $R d l^{[M D-R R]}$ embryos and cultures made from these embryos were homozygous for the A302S point mutation.

Electrophysiology. Postsynaptic currents (PSCs) were recorded with whole-cell pipettes $(3-8 \mathrm{M} \Omega$ ) filled with internal solution containing the following (in mM): $120 \mathrm{CsOH}, 120$ D-gluconic acid, $0.1 \mathrm{CaCl}_{2}, 2 \mathrm{MgCl}_{2}$, $20 \mathrm{NaCl}, 1.1 \mathrm{EGTA}$, and $10 \mathrm{HEPES}, \mathrm{pH}$ 7.2. In many of the recordings, 4 mM ATP was also added to the internal solution to prevent rundown of the currents. Recordings performed with elevated internal $\mathrm{Cl}^{-}$concentrations were obtained using an internal solution in which $\mathrm{CsCl}(120 \mathrm{~mm})$ was substituted for $\mathrm{CsOH}$ and D-gluconic acid. The external solution contained the following (in mM): $140 \mathrm{NaCl}, 1 \mathrm{CaCl}_{2}, 4 \mathrm{MgCl}_{2}, 3 \mathrm{KCl}$, and 5 HEPES, pH 7.2. All data shown are corrected for the $5 \mathrm{mV}$ liquid junction potential generated in these solutions. IPSCs recorded in the absence of tetrodotoxin (TTX) were defined as spontaneous IPSCs (sIPSCs), and those recorded in the presence of $1 \mu \mathrm{M}$ TTX were defined as miniature IPSCs (mIPSCs). Glutamate and GABA-evoked currents were recorded in the whole-cell configuration, at a holding potential of $0 \mathrm{mV}$, in response to puffer application of agonist. Extracellular recordings of action potentials (APs) were obtained using the cell-attached recording configuration. In comparisons of electrophysiological data between wild-type and $R d l$ mutant cultures, all recordings were performed blind with respect to genotype. The following drugs were bath applied in specific experiments: D-tubocurarine (curare; $1 \mu \mathrm{M}), \mathrm{BMC}(100 \mu \mathrm{M})$, and/or PTX $(0.05-100 \mu \mathrm{M})$. Data were acquired with an Axopatch 200B (Axon Instruments, Foster City, CA) or List EPC7 amplifier (Adam-List Associates, Westburg, NY), a Digidata 1320A digital-to-analog converter (Axon Instruments), a Dell (Dimension 4100) computer (Dell Computer Company, Round Rock, TX), and pClamp8 (Axon Instruments) software. Recordings were made at room temperature between 2 and 9 DIV.

Analysis of GABAergic mIPSCs. Individual mIPSCs were detected using miniature PSC detection software (MiniAnalysis Program; Synaptosoft, Decatur, GA) with a threshold criteria for individual events of $5 \mathrm{pA}$ (twofold greater than the $2.5 \mathrm{pA}$ root mean square noise level). In addition, events were accepted for kinetics analysis only if the shape was asymmetrical with a fast-rising and more slowly decaying falling phase. Current traces were filtered at $2 \mathrm{kHz}$ and digitized at $10-20 \mathrm{kHz}$ using pClamp8 software. The mean amplitude and rise time were determined from the ensemble average mIPSCs assembled from $\geq 14$ single events in each neuron. Decay time constants were determined by fitting a single exponential distribution to the falling phase of the ensemble average
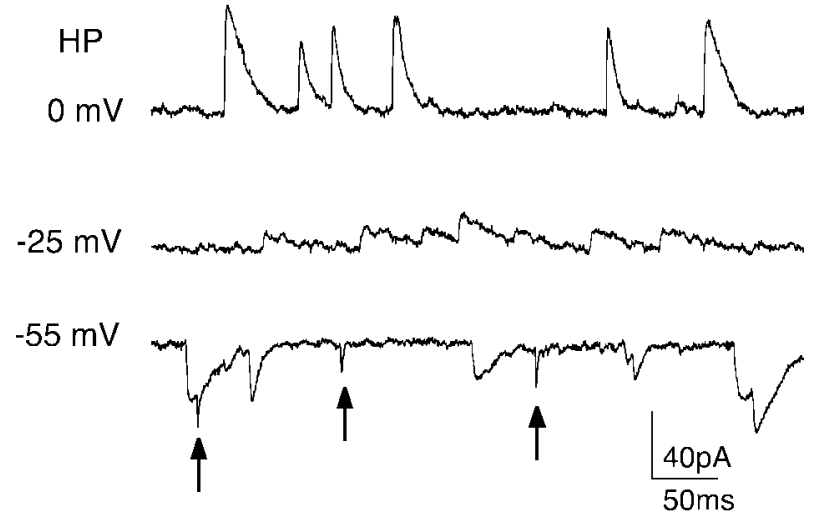

Figure 1. $\quad$ SPSCs in a cultured embryonic Drosophila neuron. Whole-cell recordings reveal slowly decaying outward currents at holding potentials (HP) of 0 and $-25 \mathrm{mV}$ in a single neuron. Holding the cell at the more negative potential of $-55 \mathrm{mV}$ reveals that, in addition to the slowly decaying GABAergic currents (inward at this potential), there are also cholinergic EPSCS (arrows) recognized by the more rapid decay kinetics.

mIPSC from each neuron. Ensemble average mIPSCs with rise times $>1.4$ msec were excluded from this analysis. mIPSC frequency in a single neuron was determined from continuous recordings of at least $1 \mathrm{~min}$ in duration.

GABA staining and analysis. Neurons were fixed with $4 \%$ paraformaldehyde for $30 \mathrm{~min}$ at room temperature. After three washes with PBS-4\% BSA, the neurons were treated with $0.1 \%$ Triton X-100 for 30 min. The primary antibody (rabbit polyclonal anti-GABA antibody; Sigma, St. Louis, MO) was used at a dilution of $1: 1000$ in a $4^{\circ} \mathrm{C}$ overnight incubation. A peroxidase-conjugated donkey anti-rabbit secondary antibody was used at a dilution of 1:50 in a $1 \mathrm{hr}$ room temperature incubation. The staining was visualized with a nickel-enhanced DAB reaction. To determine the percentage of GABA-positive neurons, two fields of view on each coverslip were randomly selected, and both the number of GABA positive neurons and the total number of neurons were counted. These numbers were averaged, and the mean percentage of GABApositive neurons was determined for each coverslip. Counts were made from eight or more coverslips at each of the ages examined.

\section{Results}

\section{GABAergic transmission mediated by PTX-sensitive chloride} channels in wild-type neurons

Embryonic Drosophila neurons grown in DDM1 form spontaneously active synaptic connections with each other (Lee and O'Dowd, 1999). Initial experiments revealed the presence of slowly decaying GABAergic sPSCs, outward currents at $0 \mathrm{mV}$ in $39 \%$ ( 23 of 59 cells) of the neurons examined at 3-4 d in vitro (Fig. 1, top trace). However, rapidly decaying cholinergic sEPSCs were also seen in $80 \%$ of these neurons when the holding potential was at or below $-55 \mathrm{mV}$ (Fig. 1, bottom trace). Therefore, to quantitatively examine the properties of GABA receptormediated synaptic currents in isolation, GABAergic currents were recorded in the presence of curare $(1 \mu \mathrm{M})$ to block the nictotinic aceytylcholine receptors and/or at $0 \mathrm{mV}$, the reversal potential for the cholinergic currents.

The relationship between the reversal potential of the GABAergic sPSCs and chloride concentration was examined in the presence of curare. Ensemble average currents recorded at a variety of holding potentials, from a single neuron in the standard recording conditions $\left(24 \mathrm{mM} \mathrm{Cl}^{-}{ }_{\text {in }} / 153 \mathrm{mM} \mathrm{Cl}^{-}\right.$out $)$, are illustrated in Figure $2 \mathrm{~A}$. Currents are inward at -75 and $-95 \mathrm{mV}$ and outward at $-15 \mathrm{mV}$ and above. The current-voltage relationship for this cell reveals an extrapolated reversal potential of -44.5 $\mathrm{mV}$ (Fig. $2 \mathrm{~B}$ ). The mean reversal potential was $-41.5 \pm 2.1 \mathrm{mV}$ 
A

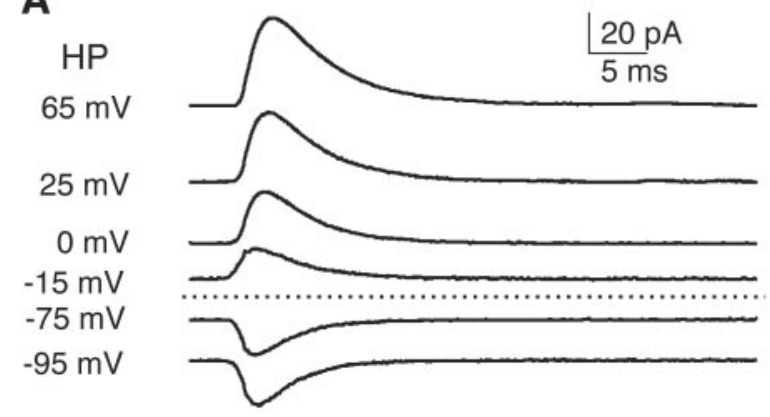

\section{B}

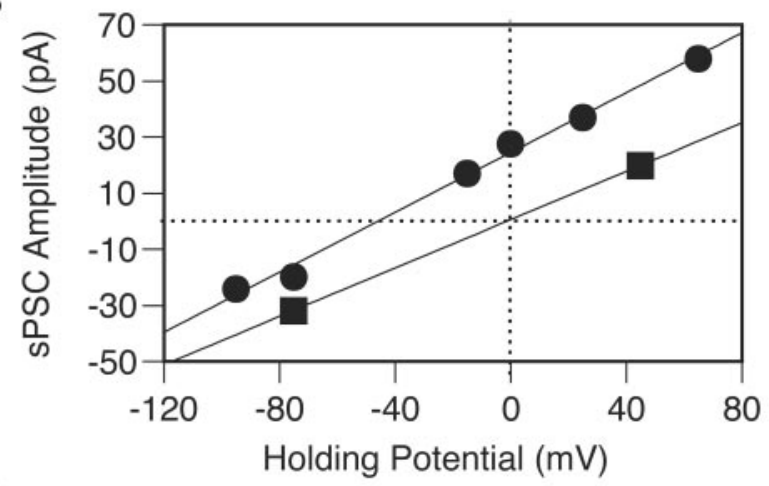

C

Control

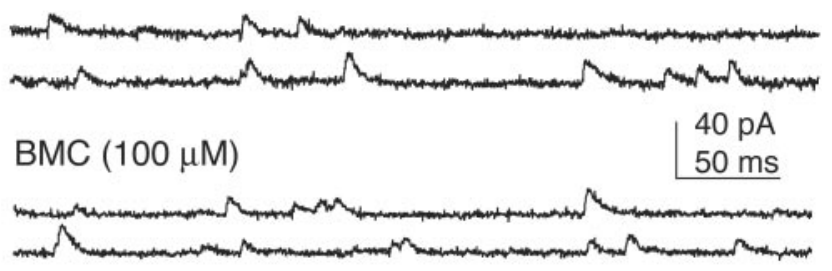

PTX $(10 \mu \mathrm{M})+$ BMC $(100 \mu \mathrm{M})$

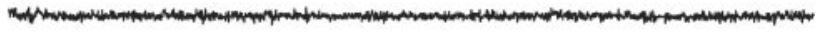

Wash
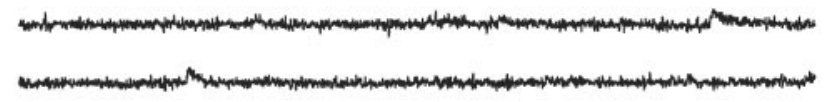

D

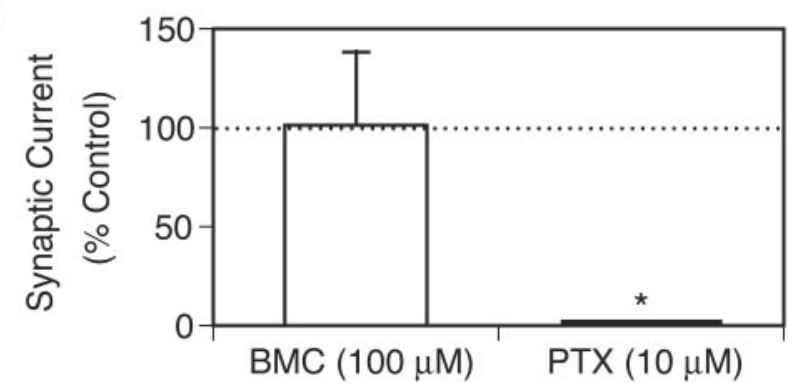

Figure 2. Reversal potential and pharmacology of the GABAergic PSCS. A, Ensemble averages of sPSC 5 at indicated holding potentials (HP) from a single neuron. Each sPSC is the average of $\geq 25$ individual sPSCS. $B$, The amplitude of the ensemble average sPSCs plotted as a function of the holding potential in the standard recording conditions with internal chloride ( $24 \mathrm{~mm}$ ), external chloride ( $153 \mathrm{~mm}$; circles), and in symmetrical chloride (squares). A linear regression fit to the data indicates $x$-intercepts of -44.5 and $0 \mathrm{mV}$, respectively, close to the theoretica equilibrium potential for chloride in the two conditions. C, GABAergic synaptic currents recorded at $0 \mathrm{mV}$ from a single neuron are not blocked by bath application of $100 \mu \mathrm{M}$ BMC but are $(n=5)$, close to the calculated chloride equilibrium potential of $-45 \mathrm{mV}$. In symmetrical chloride, the $I-V$ curve shifts to the right with an extrapolated reversal potential of $-1.1 \pm 2.6 \mathrm{mV}$, as predicted for a chloride-mediated current (Fig. 2B).

Previous studies have demonstrated that there are at least two pharmacologically distinct Drosophila GABA receptors based on their sensitivity to PTX and BMC (Zhang et al., 1995). As illustrated in Figure $2 C$, outward synaptic currents in embryonic Drosophila neurons were still observed in the presence of a high concentration $(100 \mu \mathrm{M})$ of BMC but were blocked by $10 \mu \mathrm{M}$ PTX. Partial blockade of receptors can lead to both a reduction in charge transfer per synaptic event, and a decrease in event frequency as they fall below the detection threshold and into the noise. To quantitatively describe the effect of BMC and PTX, the synaptic current remaining after drug treatment in each cell was calculated using the following formula: synaptic current (\% control $)=\left(f q_{A} / f q_{B}\right) \times 100$, where $f$ is the event frequency, and $q$ is the mean charge transfer per event determined from the ensemble average synaptic current before $(B)$ and after $(A)$ drug treatment. As illustrated in Figure 2D, $100 \mu \mathrm{M}$ BMC did not cause a significant reduction in the GABAergic synaptic currents. In contrast, $10 \mu \mathrm{M}$ PTX resulted in a large $(>99 \%)$ and significant decrease in the synaptic currents (Fig. 2D). This indicates that the majority of the receptors mediating the synaptic GABAergic currents in the cultured neurons are pharmacologically similar to the Rdl homomultimers observed in oocytes and the receptors mediating GABA-evoked currents in cultured larval neurons (Zhang et al., 1995).

In addition to GABA receptors, invertebrates including Drosophila express glutamate-gated chloride channels that show varying sensitivity to PTX (Cully et al., 1996; Etter et al., 1999). In the absence of pharmacological agents that specifically block the glutamate-gated chloride channels, we compared the PTX sensitivity of GABA- with glutamate-evoked currents in the cultured neurons. Puffer application of GABA evoked robust outward currents in the cultured neurons clamped at $0 \mathrm{mV}$ (Fig. $3 A$ ). Similar to the synaptic currents, the GABA-evoked currents were very sensitive to PTX, with the peak amplitude reduced by $>95 \%$ in $1 \mu \mathrm{M}$ PTX and by $>99 \%$ in $10 \mu \mathrm{M}$ PTX (Fig. $3 A, C$ ). L-Glutamate $(100 \mu \mathrm{M})$ also evoked outward currents in cultured neurons clamped at $0 \mathrm{mV}$ (Fig. $3 B$ ), demonstrating that glutamate-gated chloride channels are indeed present in the embryonic Drosophila neurons. However, $1 \mu \mathrm{M}$ PTX did not significantly reduce the amplitude of the glutamate-evoked current, and $10 \mu \mathrm{M}$ PTX caused only a slight reduction (Fig. 3 B, C). Therefore, because the majority of the synaptic currents recorded at 0 $\mathrm{mV}$ in wild-type neurons are blocked by $1 \mu \mathrm{M}$ PTX (95\% reduction) (see Fig. 9A), glutamate-gated chloride channels are not likely to contribute significantly to the PTX-sensitive synaptic currents described in this study. This suggests that the vast majority, if not all, of chloride-mediated synaptic currents are the result of activation of GABA-gated receptors.

$\leftarrow$

completely blocked by $10 \mu \mathrm{M}$ PTX. The PTX inhibition was partially reversed after a 20 min wash with a PTX-free recording solution. D, Bath perfusion of BMC (100 $\mu \mathrm{m})$ did not cause a significant decrease in the synaptic currents $(n=6)$. In contrast, bath application of PTX (10 $\mu \mathrm{M})$ resulted in a dramatic and significant reduction in the synaptic currents $\left({ }^{*} p<0.05\right.$; paired Student's $t$ test; $n=7)$. Synaptic current (percentage of control) is defined as charge transfer per event multiplied by the event frequency after drug (BMC or PTX) treatment, normalized to the pretreatment value in each cell. Error bars indicate SEM. 
A

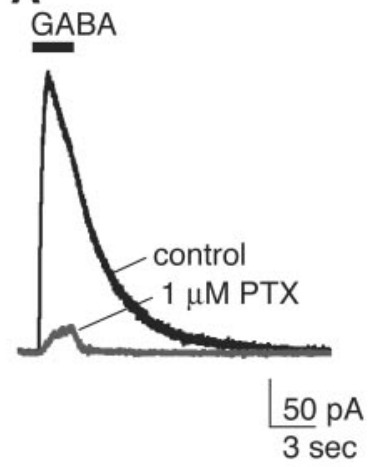

C

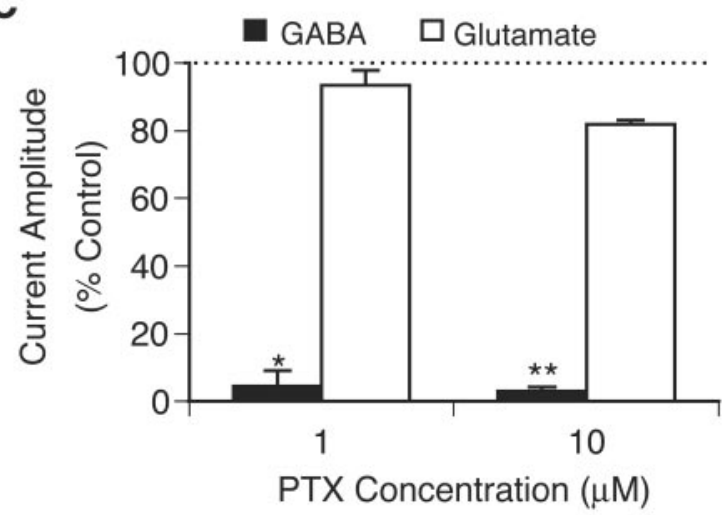

Figure 3. GABA- and glutamate-evoked currents exhibit a differential sensitivity to PTX blockade. A, Pressure ejection of $100 \mu \mathrm{m}$ GABA evokes a large outward current in an embryonic neuron held at $0 \mathrm{mV}$ in standard recording solutions. Bath application of $1 \mu \mathrm{M}$ PTX blocks the majority of the current. $B$, Pressure ejection of $100 \mu \mathrm{m} \mathrm{L}$-glutamate evokes an outward current in a second embryonic neuron held at $0 \mathrm{mV}$ in the standard recording solutions. Bath application of $1 \mu \mathrm{m}$ PTX does not affect the size or shape of the glutamate-evoked current. C, The amplitude of the evoked current after addition of the indicated concentration of PTX was normalized to the current amplitude measured before addition of the drug. The mean reduction in current amplitude (percentage of control) is plotted for both GABA- and glutamate-evoked currents at two different PTX concentrations. Both 1 and $10 \mu \mathrm{M}$ PTX resulted in a large and significant reduction in amplitude of the GABA-evoked currents $\left({ }^{*} p<0.05 ;{ }^{* *} p<0.01\right.$; paired Student's $t$ test; $n=$ 4 and 3 , respectively). In contrast, there is little change in the amplitude of the glutamateevoked currents after application of 1 and $10 \mu \mathrm{M}$ PTX ( $n=5$ and 4, respectively). Error bars indicate SEM.

\section{PTX-sensitive GABA receptors mediate inhibition}

Although GABA generally acts as an inhibitory neurotransmitter, GABA can be excitatory during early development in the mammalian CNS (Ben-Ari et al., 1997). To determine whether PTXsensitive GABA receptors mediate excitation or inhibition in the embryonic Drosophila neurons, we monitored neuronal activity levels in wild-type neurons after exposure to $10 \mu \mathrm{M}$ PTX. An increase in overall neuronal excitability during application of PTX to the culture would indicate that the PTX-sensitive GABA receptors are actively mediating inhibition in the absence of external stimuli. Conversely, a decrease in neuronal activity would suggest that these receptors, under control conditions, are mediating excitation. No change would indicate that the spontaneously occurring GABAergic PSCs do not influence activity levels in the neural circuits formed in culture. In these experiments, spontaneous action potentials were examined in single neurons within morphologically interconnected groups of cells. The recordings were performed using the cell-attached configuration to eliminate the potential complications caused by altering the driving force on chloride that occurs in whole-cell recording mode.
A

wild-type
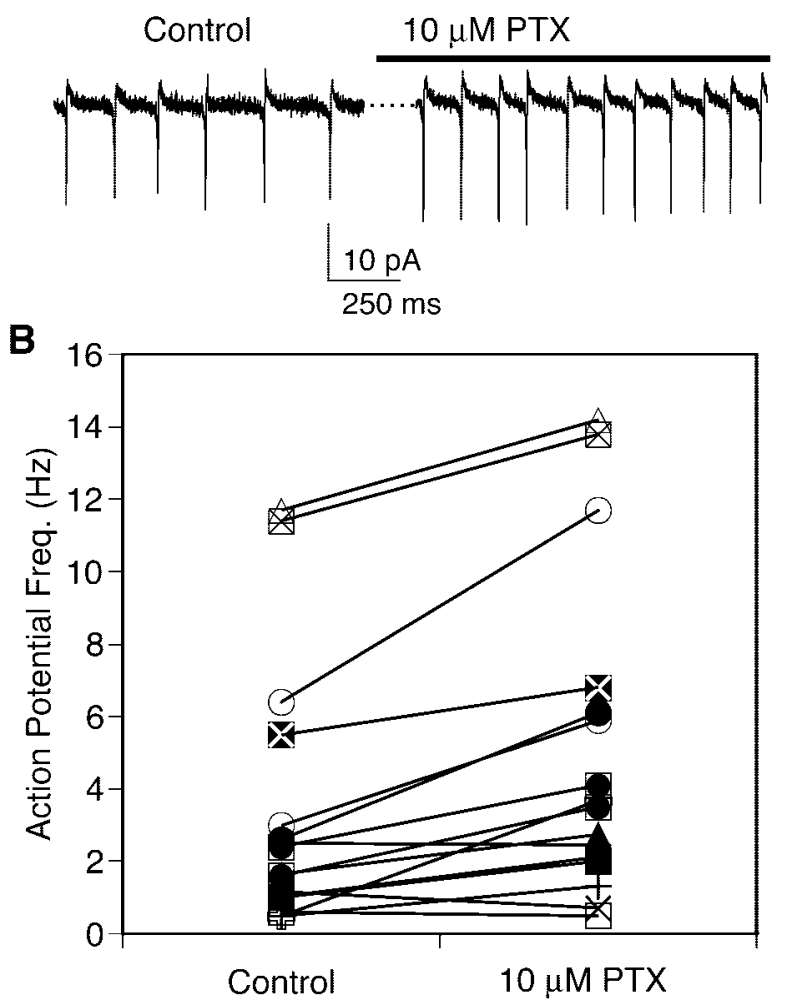

Figure 4. PTX induces an increase in neuronal excitability in wild-type cultures. A, Spontaneous extracellular sodium-dependent action potentials recorded from a wild-type neuron in physical contact with neighboring neurons using a cell-attached recording pipette. The addition of $10 \mu \mathrm{M}$ PTX results in a sustained increase in action potential frequency (dotted line indicates 1.5 min time interval required to perfuse in PTX). $B$, The frequency of spontaneous APs before (control) and after PTX is plotted as a pair for each of 15 neurons examined between 2 and $7 \mathrm{~d}$ in vitro. The AP frequency after PTX is significantly higher than before $\operatorname{PTX~(~} p<0.001$; paired Student's $t$ test).

As reported in a previous study, we found that $\sim 35-40 \%$ of cultured wild-type neurons exhibited spontaneous sodiumdependent action potentials (Hodges et al., 2002). For each neuron in which action potentials were observed, cells were monitored for 1-5 min to determine the mean action potential frequency. Frequency was again monitored in these same cells after bath application of $10 \mu \mathrm{M}$ PTX. As illustrated in Figure $4 A$, the blockade of the GABA receptors with PTX caused an increase in the spontaneous action potential frequency in a wild-type neuron. The action potential frequency before (control) and after PTX is shown for 15 wild-type neurons. The increase in AP frequency, from $3.2 \pm 0.7$ to $4.8 \pm 1 \mathrm{~Hz}$, was significant $(p<0.001$; paired Student's $t$ test). This increase in neuronal activity after the blockade of the GABA receptors demonstrates that spontaneous GABAergic synaptic transmission mediates inhibition in cultured embryonic neurons. Therefore, the GABAergic synaptic currents are hereafter designated IPSCs.

\section{GABAergic mIPSCs are regulated by calcium entry through voltage-gated channels}

As illustrated in Figure $5 A$, bath application of $1 \mu \mathrm{M}$ TTX to block the generation of spontaneous sodium-dependent APs resulted in small reductions in the mean amplitude ( 8.5 to $7.5 \mathrm{pA}$ ) and the frequency $(7.8$ to $5.9 \mathrm{~Hz})$ of the synaptic currents in this particular neuron. Similar decreases in synaptic current amplitude and 
A

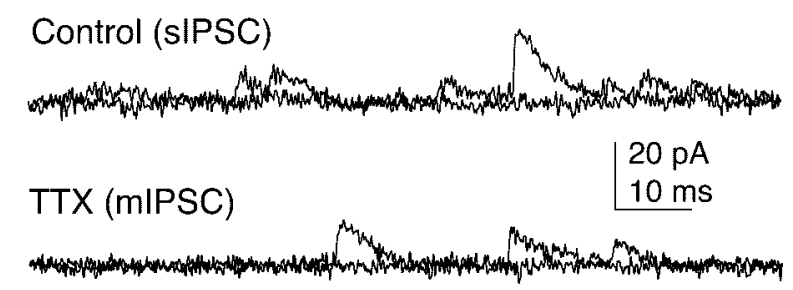

B
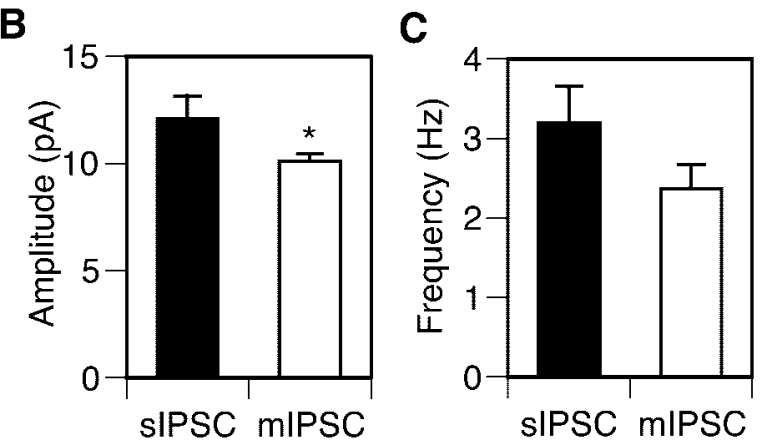

Figure 5. GABAergic IPSCs recorded in the presence and absence of TTX. $A$, sIPSCS and mIPSCs (recorded after bath perfusion of $1 \mu \mathrm{M}$ TTX) from a single neuron. $B$, The mean synaptic current amplitudes from cells examined in either normal external saline (SIPSC, $n=28$ ) or in TTX (mIPSC, $n=42$ ). The mIPSC amplitude is $\sim 20 \%$ smaller than the sIPSC amplitude ( $p<$ 0.05; unpaired Student's $t$ test). C, The mean mIPSCs frequency in this same population of cells is also lower than the SIPSCs, but the difference is not significant. Recordings were made at $0 \mathrm{mV}$ in the presence of $1 \mu \mathrm{m}$ curare. Error bars indicate SEM.

frequency were observed in 8 of 12 neurons after TTX application, suggesting that AP release does contribute to the synaptic currents in some cells. To evaluate the relative contribution of AP-dependent release, the mean amplitude and frequency of the synaptic currents recorded from 28 neurons in normal external solution was compared with the mean amplitude and frequency recorded in an independent set of neurons examined in TTX (Fig. $5 B)$. Comparison of these data using a Student's unpaired $t$ test revealed a small $(\sim 20 \%)$ but significant $(p<0.05)$ reduction in the amplitude of the currents recorded in TTX. Although the mean frequency was also less in the TTX group, the variance was large and the difference was not statistically significant. Together, these data suggest that, although spontaneous sodiumdependent APs in the cultured neurons can drive synaptic release of GABA, many spontaneous synaptic currents are TTX resistant and therefore sodium AP-independent. Events recorded in TTX are defined as GABAergic mIPSCs.

To determine whether sodium AP-independent flux of calcium can regulate GABAergic mIPSCs, as demonstrated previously for the cholinergic mEPSCs in these cultured neurons (Lee and O'Dowd, 1999), we examined the effects of removing calcium from the recording solution. mIPSCs were recorded in normal external saline containing $1 \mathrm{~mm}$ calcium and, after replacement of the bathing medium, with $0 \mathrm{mM} \mathrm{Ca}^{2+}$ (Fig. 6A). There was a large significant decrease in the mean mIPSC frequency after removal of the external calcium (Fig. 6A,B). To determine whether the calcium-dependent regulation of GABAergic mIPSC frequency is mediated by the entry of calcium through voltagegated channels, the consequence of the addition of $3 \mathrm{mM} \mathrm{Co}^{2+}$ to the normal external saline containing $1 \mathrm{~mm}$ calcium was examined. The addition of $\mathrm{Co}^{2+}$ also caused a dramatic and significant decrease in mIPSC frequency in the cultured neurons (Fig. 6B). This demonstrates that AP-independent influx of calcium ions,
A

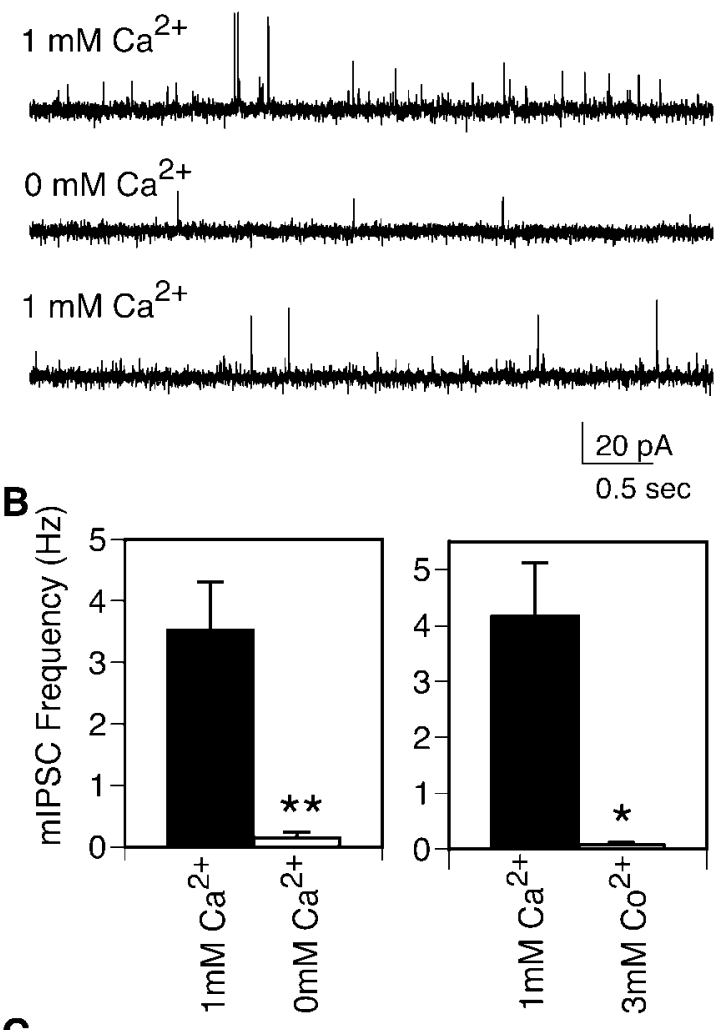

C

Tonic mIPSCs
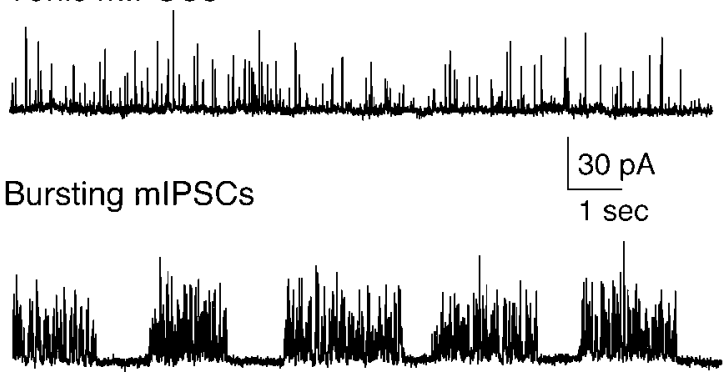

Figure 6. GABAergic mIPSC frequency is regulated by voltage-gated calcium channel activity. $A$, The frequency of mIPSCs recorded from a single neuron in $1 \mathrm{~mm}$ external calcium is reversibly reduced when calcium is removed from the external solution $\left(0 \mathrm{~mm} \mathrm{Ca}^{2+}\right) . B$, The average $\mathrm{mIPSC}$ frequency examined in an external solution containing $1 \mathrm{~mm} \mathrm{Ca}^{2+}$ followed by examination in either $0 \mathrm{mM} \mathrm{Ca}^{2+}(n=6)$ or $3 \mathrm{mMCO}^{2+}(n=4)$. There is a large significant reduction in the mean frequency in both conditions when compared with the standard $1 \mathrm{mM}$ external calcium saline $\left({ }^{*} p<0.05 ;{ }^{* *} p<0.01\right.$; paired Student's $t$ test). C, Longer-duration records from two different neurons illustrate the tonic and bursting patterns of synaptic currents recorded in TTX (mIPSCs). Recordings were made at $0 \mathrm{mV}$ in the presence of $1 \mu \mathrm{m}$ curare and $1 \mu \mathrm{M}$ TTX.

through voltage-gated calcium channels, influences the probability of GABA release from the presynaptic terminals in the absence of externally applied stimuli.

Inspection of long-duration recordings revealed that, in most of the cell examined (75\%), the synaptic currents appeared to occur at random intervals (Fig. $6 C$, top trace). However, in $\sim 25 \%$ of the cells the currents occurred in bursts, and, unexpectedly, this burst activity was not blocked by TTX. mIPSCs appearing in bursts, with regular interburst intervals, were observed in $\sim 10 \%$ of neurons (Fig. 6C, bottom trace). Another 15\% of the cells exhibited irregular bursting in which the interburst interval was variable. The appearance of mIPSC bursts, in the presence of 


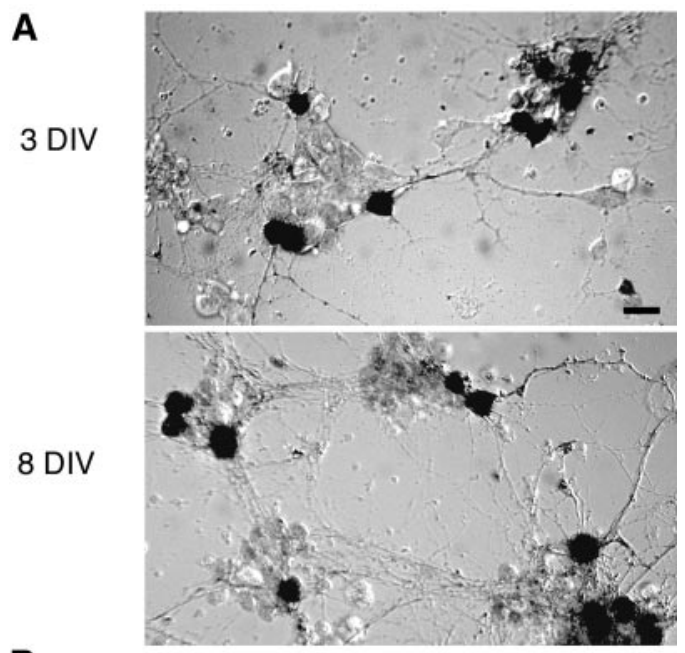

B

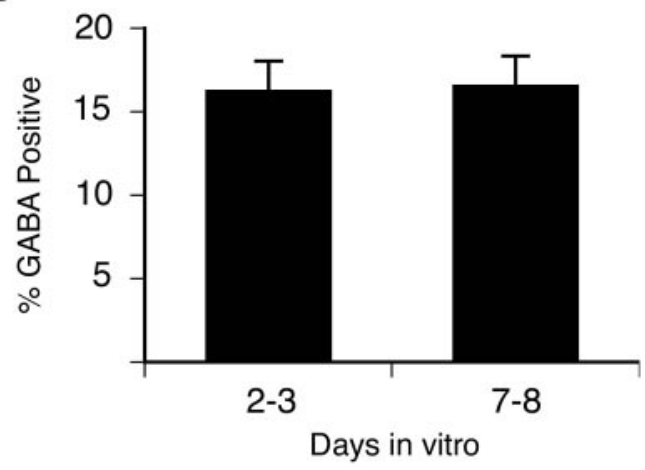

Figure 7. The percentage of GABAergic neurons does not change during the first week in culture. $A$, Cultures fixed and stained with anti-GABA antibodies at 3 and 8 DIV reveal a subpopulation of GABA-positive neurons. Scale bar, $10 \mu \mathrm{m}$. B, GABA-positive neurons represent $\sim 16 \%$ of the total population in 2- to 3 -d-old cultures, and this does not change over time in vitro. Error bars indicate SEM.

TTX, demonstrates multiquantal release of neurotransmitter in the absence of sodium-dependent APs.

\section{Maturational change in the mIPSC decay kinetics}

Previous studies in the mammalian CNS, both in vivo and in vitro, have demonstrated that a number of different aspects of fast GABAergic synaptic transmission are developmentally regulated. To determine whether GABAergic transmission in Drosophila is also subject to maturational change, we examined neurons in culture between 2 and $8 \mathrm{~d}$ in vitro. Antibody staining demonstrated that GABA-positive neurons were found in both young and old cultures (Fig. 7A). There was no significant difference in the number of GABA-positive neurons, representing $\sim 16 \%$ of the total population, between 2 and $8 \mathrm{~d}$ in vitro (Fig. $7 B$ ). GABAergic mIPSCs were detected in $\sim 35 \%$ of neurons examined between 2 and $4 \mathrm{~d}$. Although a slight decline was observed over time, GABAergic mIPSCs were still detected in $~ 20 \%$ of the neurons between 7 and $9 \mathrm{~d}$ in vitro. The mIPSC frequency did not change significantly during the first week in culture.

To determine whether there were maturational changes in the properties of the receptors mediating GABAergic transmission, the amplitude, rise time, and decay time of the synaptic currents were examined in cells of different ages. These studies were limited to analyses of mIPSCs to focus on the properties of the receptors. Neurons were included in the data set if at least 14 individual mIPSCs were recorded (average number was 75) and the
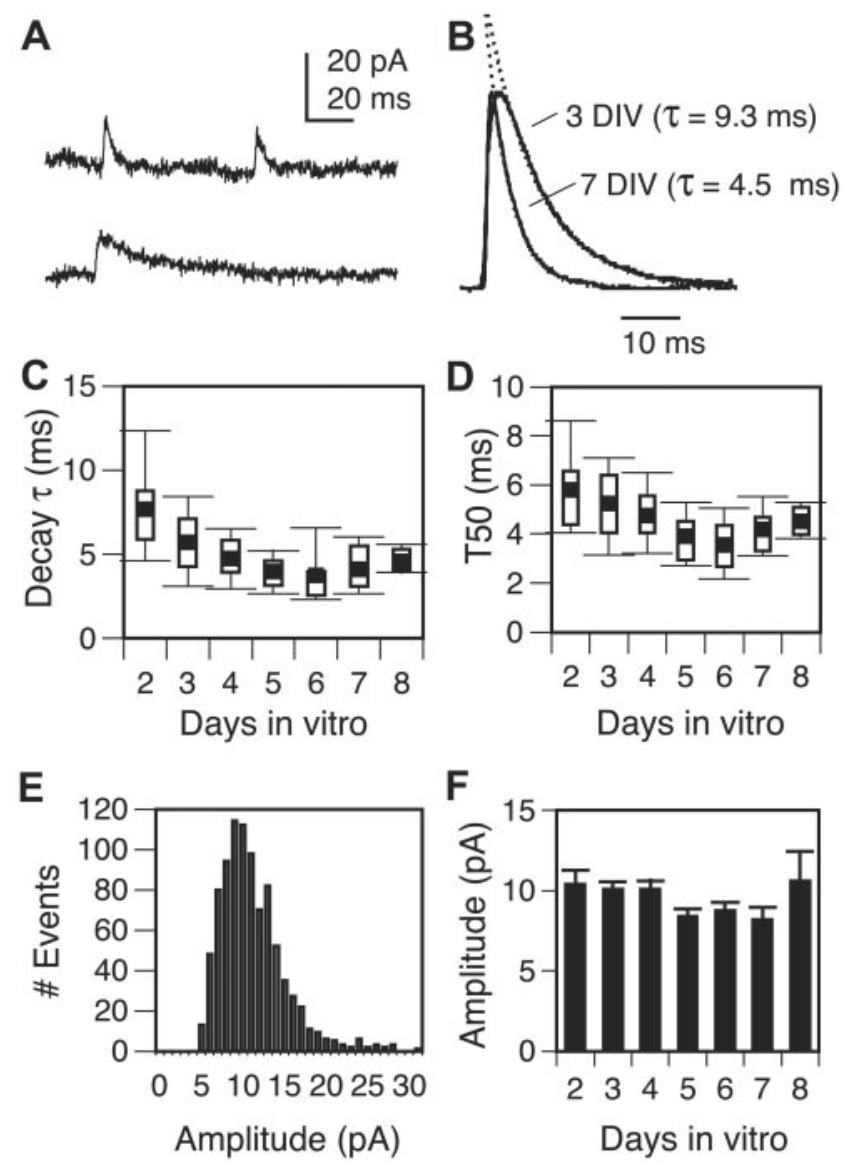

Figure 8. Increase in mean rate of decay of GABAergic mIPSCs during early development. $A$ Examples of fast and slow decaying mIPSCs recorded from a single neuron at $6 \mathrm{~d}$ in vitro. $B$, Ensemble average mIPSCs recorded from two neurons at 3 and $7 \mathrm{~d}$ in vitro. Traces were normalized to unitary amplitude. Single exponentials (dotted lines) are fit to each curve. C, Box plot of the mean decay time constant as a function of age. The box points represent the 10th, 25th, median, 75th, and 95th percentiles. Symbols indicate mean. Despite a large variability, the mean decay time constant decreases significantly as age increases $(p<0.0001$; one-way ANOVA). D, A box plot of the mIPSC duration measure at $50 \%$ amplitude $\left(T_{50}\right)$ for the same population of neurons. This reveals variability within an age group as well and a smaller but still significant decrease in the $\mathrm{T}_{50}$ as a function of increasing age ( $p<0.01$; one-way ANOVA). $E$, The mIPSC amplitude varies widely in a single neuron, and the amplitude distribution is positively skewed. $F$, The mean mIPSC amplitude does not change significantly over time in vitro. Recordings were made at $0 \mathrm{mV}$ in the presence of $1 \mu \mathrm{m}$ curare and $1 \mu \mathrm{M}$ TTX.

frequency was $>0.1 \mathrm{~Hz}$. In addition, to reduce the contribution of potential differences in channel localization to kinetics properties, ensemble averages with rise times slower than $1.4 \mathrm{msec}$ were not considered for kinetics analysis.

The mIPSC decay kinetics properties varied both among cells and, in some cases, within a cell (Fig. 8A). This demonstrates functional heterogeneity in the properties of the receptors mediating the GABAergic mIPSCs. To examine the decay kinetics as a function of age, the falling phase of the ensemble average mIPSC from each cell was fit with a single exponential, and the time constant was determined. The majority of ensemble average currents were well fit with a single exponential (Fig. $8 \mathrm{~B}$ ). However, in some cases in which a single cell exhibited a population of both fast- and slow-decaying mIPSCs, the data could not be fit with a single exponential. Therefore, we also determined the $T_{50}$ (the time for the mIPSC to decay to half-amplitude) because this measurement is not dependent on the goodness-of-fit of an exponential. Although there was considerable variability in both of these 
Table 1. GABAergic synaptic currents recorded from wild-type and $R d /$ mutant cultures

\begin{tabular}{|c|c|c|c|c|c|}
\hline Genotype & Incidence (\%) & mIPSC Freq (Hz) & mIPSC Amp (pA) & mIPSC decay time (msec) & mIPSC rise time (msec) \\
\hline Wild type & $30 \pm 2(n=64)$ & $2.8 \pm 0.4(n=67)$ & $9.9 \pm 0.3(n=88)$ & $5.4 \pm 0.3(n=88)$ & $0.88 \pm 0.03(n=88)$ \\
\hline Rdl & $25 \pm 2(n=54)$ & $2 \pm 0.4(n=30)$ & $9.9 \pm 0.5(n=49)$ & $5 \pm 0.3(n=49)$ & $0.91 \pm 0.04(n=49)$ \\
\hline
\end{tabular}

The probability of detecting GABAergic mIPSCS and their biophysical properties are similar in wild-type and RdI mutant neurons examined between 2 and $9 \mathrm{~d}$ in vitro. Mean \pm SEM are shown. Freq, Frequency; Amp, amplitude.

values at each age examined, both the decay time constant and the $T_{50}$ decreased significantly as a function of age in culture (Fig. $8 C, D)$. Histograms of mIPSC amplitudes in single cells were characterized by a positively skewed distribution (Fig. $8 E$ ). The mean $\mathrm{MIPSC}$ amplitude, determined from the ensemble average mIPSC, ranged from 5.5 to $22 \mathrm{pA}$ in the population of cells examined. However, the mean mIPSC amplitude did not change significantly between 2 and $8 \mathrm{~d}$ in culture (Fig. $8 F$ ). The mean $10-90 \%$ rise time of the ensemble average mIPSCs was $\sim 1 \mathrm{msec}$, and this did not change over time (data not shown). Together, these data indicate that the GABA receptors mediating synaptic transmission are functionally heterogenous at all ages. In addition, there is shift during maturation in culture toward an increase in the contribution of receptors governing the more rapidly decaying currents.

GABA receptors containing Rdl subunits mediate inhibitory synaptic transmission in culture

Expression studies demonstrating that the Rdl GABA receptor subunit can form PTX-sensitive, BMC-insensitive homooligomeric channels in Xenopus oocytes suggest that this is a good candidate for contributing to the receptors mediating the synaptic mIPSCs in Drosophila neurons. To investigate this possibility, cultures were prepared from $R d l$ homozygous mutant embryos. The strain used has a point mutation (A302S) in the Rdl receptor subunit that results in a resistance to dieldrin in the animal and reduced PTX sensitivity in mutant channels expressed in oocytes (ffrench-Constant et al., 1993a). Therefore, if Rdl subunits contribute to the receptors mediating the synaptic currents, the GABAergic mIPSCs in the mutant neurons should exhibit a decreased sensitivity to PTX blockade.

GABAergic synaptic currents, outward at $0 \mathrm{mV}$, were recorded from $\sim 25 \%$ of the neurons in $R d l$ mutant cultures, between 2 and $9 \mathrm{~d}$ in vitro, similar to the incidence observed in the wild-type cultures (Table 1). Comparison of the mean frequency, amplitude, and kinetics properties of the mIPSCs between $R d l$ mutant and wild-type neurons revealed no significant differences between the two genotypes (Table 1). In contrast, there was a marked reduction of the sensitivity of the $R d l$ mutant versus wildtype neurons to PTX blockade of the mIPSCs (Fig. 9A). These data were acquired as described previously in Figure $2 D$. Briefly, charge transfer (determined from the ensemble average) multiplied by the event frequency after drug treatment was expressed as a percentage of the pretreatment value in each cell. The doseresponse curve for the $R d l$ mutant neurons was significantly shifted to the right when compared with the wild-type curve ${ }^{*} p<0.05 ;{ }^{* *} p<0.01$; two-way ANOVA; Bonferroni post hoc analysis). The mIPSCs in $R d l$ neurons, like wild-type neurons, were not blocked by $100 \mu \mathrm{M}$ BMC (data not shown; $n=4$ ). These data, demonstrating a significant decrease in the sensitivity to PTX blockade of the mIPSCs in $R d l$ mutant versus wild-type neurons, indicate that the Rdl subunit contributes to the formation of GABA receptors involved in mediating spontaneous synaptic currents.

To determine whether Rdl-containing receptors contribute to active inhibition in addition to their role in mediating mIPSCs,
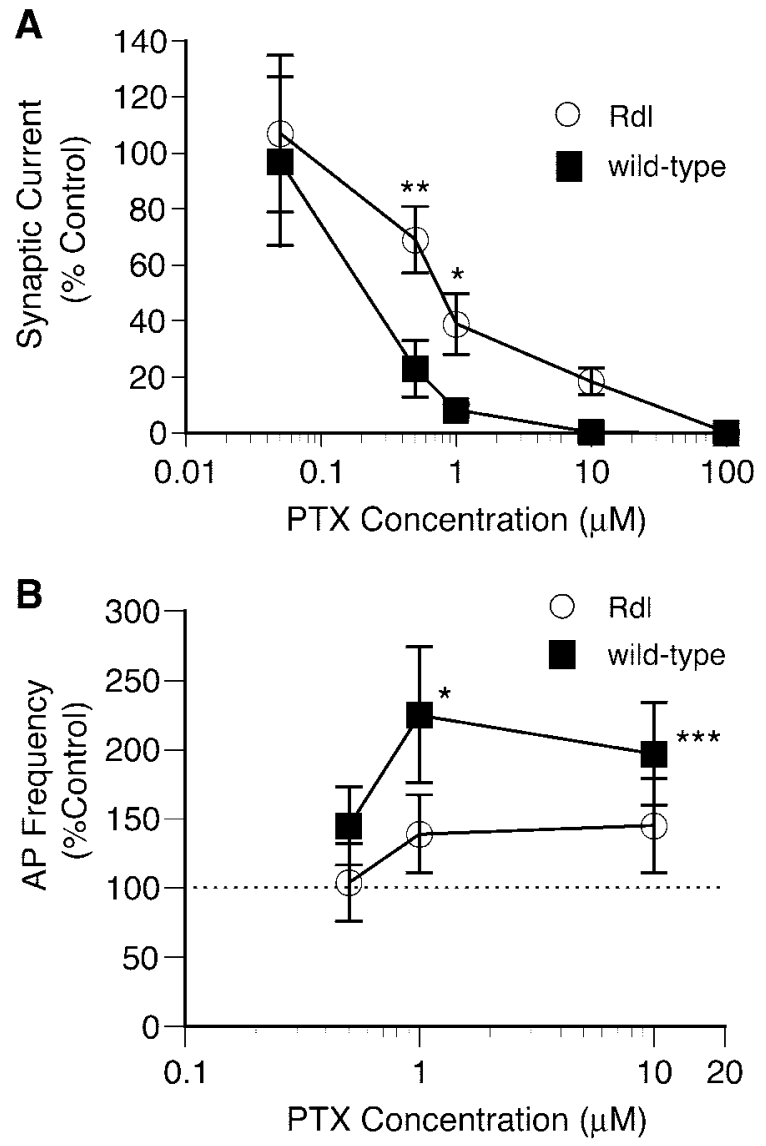

Figure 9. Rdl mutants exhibit reduced sensitivity to PTX-blockade of the mIPSCs and resistance to PTX-induced increases in neuronal excitability. $A$, Wild-type and $R d l$ mutant neurons exhibit dose-dependent decreases in synaptic currents, with complete blockade occurring at $100 \mu \mathrm{M}$ PTX in both genotypes. The $R d /$ mutant curve is shifted to the right, indicating a reduction in sensitivity to PTX blockade of the synaptic currents when compared with wild type ${ }^{*} p<$ $0.05 ;{ }^{* *} p<0.01$; two-way ANOVA; Bonferroni post hoc analysis). Synaptic current (percentage of control) charge transfer per event multiplied by event frequency after drug treatment was normalized to the pretreatment value in each cell. Each point represents the mean value determined from 4, 9, 8, 9, and $5 R d /$ neurons and 4, 9, 17, 6, and 4 wild-type neurons at $0.05,0.5,1$, 10 , and $100 \mu \mathrm{m}$ PTX, respectively. Whole-cell recordings were made at $0 \mathrm{mV}$ in the presence of $1 \mu \mathrm{m}$ curare and $1 \mu \mathrm{M}$ TTX. $B$, In wild-type neurons, there is a significant increase in the mean AP frequency after bath application of 1 and $10 \mu \mathrm{M}$ PTX $\left({ }^{*} p<0.05\right.$; ${ }^{* * *} p<0.001$; paired Student's $t$ test; $n=7,10$, and 17 neurons at $0.5,1$, and $10 \mu \mathrm{M}$ PTX). In contrast, in $R d /$ neurons, the mean increase in AP frequency is less than half the magnitude observed in wild-type at each PTX concentration, and none represent significant increases ( $p>0.05$; paired Student's $t$ test; $n=$ 6,9 , and 6 neurons at $0.5,1$, and $10 \mu \mathrm{M}$ PTX). AP frequency (percentage of control) is defined as the frequency of extracellular spontaneous APs after bath application of PTX, normalized to the pretreatment frequency in each neuron. APs were recorded in the cell-attached recording configuration in normal external saline. Error bars indicate SEM.

we examined the effect of bath application of PTX on neuronal excitability in the mutant cultures. A resistance to PTX-induced increases in excitability in $R d l$ mutant cultures would support this hypothesis. As shown previously in Figure 4, the firing frequency of randomly selected wild-type neurons was rapidly and significantly increased after bath application of $10 \mu \mathrm{M}$ PTX. To establish 
the dose dependence of this effect in wild-type neurons, two additional PTX concentrations, both of which caused significant reductions of the GABAergic mIPSCs, were examined in the same excitability assay. The effects of PTX on firing frequency at all three concentrations tested were quite variable as indicated by the large SE bars (Fig. 9B). Contributions to this variance are likely to include differences in the number, and relative strength, of GABAergic and cholingeric contacts, directly or indirectly presynaptic to each neuron from which the recordings were obtained. Nevertheless, there were significant increases in neuronal firing frequency in wild-type cultures perfused with both 1 and 10 $\mu \mathrm{M}$ PTX (Fig. 9B). The mean firing frequency was also higher in $0.5 \mu \mathrm{M}$ PTX, but this increase was not significant.

In contrast, although there was a trend toward an increase in firing frequency after perfusion of both 1 and $10 \mu \mathrm{M}$ PTX in the $R d l$ mutant cultures, these were much reduced compared with wild-type (Fig. 9B). In addition, the effect of PTX application on firing frequency was not significant at any of the concentrations tested in the $R d l$ mutant cultures ( $p>0.05$; paired Student's $t$ test). The decrease in sensitivity to PTX-induced excitation in $R d l$ mutant neurons demonstrates that Rdl-containing receptors are involved in mediating spontaneously active inhibition.

\section{Discussion}

The abundant expression of acetylcholine and GABA, throughout the Drosophila CNS, suggests that these classic neurotransmitters play a major role in mediating fast synaptic transmission (Restifo and White, 1990). Recent electrophysiological studies have provided insights into the functional aspects of excitatory cholinergic transmission in Drosophila neurons (Baines and Bate, 1998; Lee and O'Dowd, 1999, 2000; Yao et al., 2000; Rohrbough and Broadie, 2002). However, virtually nothing was known about the properties of inhibitory GABAergic synaptic transmission. Our data demonstrate that the receptors mediating GABAergic currents in Drosophila neurons are PTX sensitive, heterogeneous with respect to their biophysical properties, and regulated during maturation in culture. The GABAergic currents are inhibitory, and Rdl encoded subunits contribute to the population of receptors meditating fast inhibitory synaptic transmission in neuronal networks formed in culture.

A reversal potential near the chloride equilibrium potential and blockade by low $(1 \mu \mathrm{M})$ concentrations of PTX, a potent antagonist of insect GABA receptors (Sattelle, 1990), suggested that the spontaneous IPSCs recorded in the embryonic neurons are mediated by GABA-gated chloride channels. This conclusion is also supported by the finding that, although puffing of GABA or glutamate evokes chloride currents in the cultured neurons, as predicted from a study of larval motor neurons (Rohrbough and Broadie, 2002), only the GABA-evoked currents are effectively blocked by $1 \mu \mathrm{M}$ PTX. This PTX concentration does not significantly reduce the glutamate-evoked currents. These data strongly support the hypothesis that the receptors mediating spontaneous synaptic currents are GABA-gated, as opposed to glutamategated, chloride channels.

GABA acts primarily as an inhibitory neurotransmitter in the adult CNS of both vertebrates and invertebrates (Mody et al., 1994; Hosie et al., 1997). However, there is abundant evidence that GABA can be excitatory during early development (Ben-Ari et al., 1997). Recently, it has been reported that a blockade of $\mathrm{GABA}_{\mathrm{A}}$ receptors in the neonatal rodent brain can induce increases in neuronal excitation. This indicates that GABAergic transmission can also serve an inhibitory role in hippocampal and cortical circuits during early development in mammals
(Lamsa et al., 2000; Palva et al., 2000; Wells et al., 2000). Using a similar strategy, blocking GABA receptors by bath application of PTX, we observed an increase in spontaneous neuronal firing in the Drosophila cultures. This demonstrates that embryonic neurons form spontaneously active circuits in culture and GABAergic transmission can mediate inhibition in these networks, even at this early developmental stage in Drosophila. Future studies will be necessary to determine whether GABA can be depolarizing and/or elicit action potentials, as observed in some neurons from the early postnatal rodent brain, in subpopulations of Drosophila neurons.

At many chemical synapses, some portion of the vesicular release of neurotransmitter is AP independent. In cultured embryonic Drosophila neurons, much of the spontaneous release of GABA at synapses appears to occur in the absence of sodium spikes in presynaptic neurons. A blockade of the mIPSCs by removal of external calcium or the addition of cobalt demonstrates that these events are dependent on flux of calcium through voltage-gated channels in the presynaptic neurons. Spontaneously occurring calcium-dependent APs, such as those observed in young Xenopus neurons (Spitzer et al., 1994), could result in transient changes in levels of calcium in the presynaptic terminals that would in turn regulate vesicular release of GABA. However, this seems unlikely in the Drosophila cultures because, although many of the neurons fire spontaneous sodium APs in normal saline, regenerative spikes have not been observed in the presence of TTX. Alternatively, small fluctuations in the resting membrane potential could regulate the opening of voltage-gated calcium channels in the presynaptic terminals. The resulting changes in intracellular calcium levels would in turn influence the frequency of spontaneous fusion events. This seems plausible, given the relatively depolarized resting potential of the embryonic neurons and calcium channels that activate at voltages as low as $-60 \mathrm{mV}$ (O'Dowd, 1995; Hodges et al., 2002). In a similar manner, the unexpected appearance of mIPSCs in bursts could arise from regular oscillations in the membrane potential of a population of presynaptic GABAergic neurons in which peaks, associated with high intracellular calcium levels, may trigger the release of multiple quanta. Calcium imaging studies, in combination with electrophysiological recording, should be useful in elucidating the mechanisms underlying the AP-independent burst activity observed in the embryonic Drosophila neurons.

In mammals, there is a high degree of heterogeneity in GABA receptor properties in neurons from different regions of the CNS. Factors influencing functional heterogeneity include receptor subunit composition and desensitization rates (Vicini, 1999). In addition, the functional properties of receptors mediating synaptic currents in individual neurons can change during development. For example, there is a maturational progression from mIPSCs with slow to more rapid decay kinetics correlated with changes in receptor subunit composition and populations of cerebellar, hippocampal, cortical, and thalamic neurons (Tia et al., 1996; Hollrigel and Soltesz, 1997; Dunning et al., 1999; Huntsman and Huguenard, 2000). The heterogeneity in the decay kinetics of currents recorded from embryonic Drosophila neurons during the first week in culture is consistent with the expression of multiple receptor subtypes. This is not surprising, given that the cultures are prepared from whole embryos and therefore contain neurons from all parts of the nervous system. The shift in mean decay time constant, 1.5- to 2-fold during the first week in culture, suggests that functional properties of receptors mediating the GABAergic mIPSCs in Drosophila neurons are also subject to regulation during maturation. In rodent cortical neurons, a 
decrease in mPSC decay time constant, both in vivo and in dissociated cell culture, demonstrated that signals necessary for initiating the changes in GABA receptor function can be retained in dissociated cell culture (Dunning et al., 1999). Although we have not conducted a parallel study on GABAergic mIPSCs in Drosophila in vivo, preliminary data suggest that the GABAergic mIPSC decay rate in CNS neurons cultured from late-stage pupae are faster than those seen even in the older embryo cultures $(\mathrm{H}$. Su and D. K. O'Dowd, unpublished observations). This is consistent with the changes occurring over time in culture representing maturation that normally occurs in the animal. The evolutionary conservation of this change supports the hypothesis that alterations in GABA receptor kinetics play an important role in shaping early neural circuitry.

Cloning and expression studies have been important in defining the role of two Drosophila GABA receptor subunit genes, $R d l$ and $\mathrm{LCCH} 3$, in the formation of functional GABA-gated ion channels (Hosie et al., 1997). Our pharmacological analysis of wild-type and $R d l$ mutant neurons now provide the first insights into the subunit composition of synaptic GABA receptors in Drosophila. The PTX-sensitive mIPSCs in wild-type neurons are not blocked by BMC $(100 \mu \mathrm{M})$. This pharmacological profile is similar to homomultimeric GABA-gated chloride channels encoded by the $R d l$ GABA receptor subunit gene when expressed in Xenopus oocytes (ffrench-Constant et al., 1993a) and Sf2 cells (Zhang et al., 1995). A significant reduction of the sensitivity of the mIPSCs to blockade by PTX in $R d l$ mutant versus wild-type neurons confirmed that Rdl-encoded subunits contribute to the population of functionally active synaptic GABA receptors. Because we conducted our mutant analysis using only one $R d l$ allele, we cannot rule out the contribution of an as yet unidentified second site mutation to the observed phenotype. However, this seems unlikely for two reasons. First, previous reports indicate that the A302S amino acid substitution in the Rdl mutant strain used is responsible for the altered picrotoxin sensitivity of the mutant channels expressed in oocytes (ffrench-Constant et al., 1993a). Second, although the majority of our initial experiments on characterization of the GABAergic IPSC properties were done in Canton-S wild-type flies, most of the PTX dose-response data were gathered from an Oregon-R wild-type strain, the background of the $R d l$ mutant. There was no difference between the data from the two wild-type strains, both of which were different from the $R d l$ mutant in terms of PTX sensitivity.

The $R d l$ mutant neurons in culture exhibit a 5 - to 10 -fold reduction in PTX sensitivity based on the comparison with the wild-type dose-response curve. In contrast, the GABA-evoked currents mediated by mutant Rdl channels expressed in oocytes are $\sim 100$-fold less sensitive to PTX blockade than the wild-type Rdl channels (ffrench-Constant et al., 1993a). This suggests that synaptic GABA receptors containing $\mathrm{Rdl}$ in the neurons are heteromultimers rather than homomultimers. It does not seem likely that the receptors are Rdl- and LCCH3-encoded heteromultimers because expression studies indicate that these form PTX-insensitive, BMC-sensitive receptors (Zhang et al., 1995). In addition, antibody staining has shown that Rdl protein is localized in the synaptic neuropil in embryos and larval CNS, whereas LCCH3 is found primarily in the cell bodies, making it unlikely that they interact in vivo (Aronstein et al., 1996). Therefore, the synaptic receptors may include additional subunits, perhaps encoded by GRD (Harvey et al., 1994) or other as yet uncharacterized GABA receptor genes (Littleton and Ganetzky, 2000).

The resistance to PTX-induced increases in neuronal firing rates in $R d l$ mutant cultures demonstrates that Rdl subunit- containing GABA receptors actively mediate synaptic inhibition in Drosophila neural circuits. Therefore, it is possible that synaptically localized Rdl-containing receptors are involved in higherorder functions such as GABA receptor-mediated synchronization of neural activity known to be important in olfactory information-processing locusts (MacLeod and Laurent, 1996). Manipulation of Rdl expression in Drosophila should make it possible to test this hypothesis.

\section{References}

Aronstein K, Auld V, ffrench-Constant R (1996) Distribution of two GABA receptor-like subunits in the Drosophila CNS. Invert Neurosci 2:115-120.

Baines RA, Bate M (1998) Electrophysiological development of central neurons in the Drosophila embryo. J Neurosci 18:4673-4683.

Ben-Ari Y, Khazipov R, Leinekugel X, Caillard O, Gaiarsa J-L (1997) $\mathrm{GABA}_{\mathrm{A}}, \mathrm{NMDA}$ and AMPA receptors: a developmentally regulated "menage a trois." Trends Neurosci 20:523-529.

Buchner E, Bader R, Buchner S, Cox J, Emson PC, Flory E, Heizmann CW, Hemm S, Hofbauer A, Oertel WH (1988) Cell-specific immuno-probes for the brain of normal and mutant Drosophila melanogaster. Cell Tissue Res 253:357-370.

Cully DF, Paress PS, Liu KK, Schaeffer JM, Arena JP (1996) Identification of a Drosophila melanogaster glutamate-gated chloride channel sensitive to the antiparasitic agen avermetin. J Biol Chem 271:20187-20191.

Dunning DD, Hoover C, Soltesz I, Smith M, O’Dowd D (1999) GABA A receptor-mediated miniature postsynaptic currents and $\alpha$-subunit expression in developing cortical neurons. J Neurophysiol 82:3286-3297.

Etter A, Cully DF, Liu KK, Reiss B, Vassilatis DK, Schaeffer JM, Arena JP (1999) Picrotoxin blockade of invertebrate glutamate-gated chloride channels: subunit dependence and evidence for binding within the pore. J Neurochem 72:318-326.

ffrench-Constant RH, Roush RT, Mortlock D, Dively GP (1990) Isolation of dieldrin resistance from field populations of Drosophila melanogaster. J Econ Entomol 83:1733-1737.

ffrench-Constant RH, Rocheleau TA, Steichen JC, Chalmers AE (1993a) A point mutation in Drosophila GABA receptor confers insecticide resistance. Nature 363:449-451.

ffrench-Constant RH, Steichen J, Rocheleau RA, Aronstein K, Roush RT (1993b) A single-amino acid substitution in a $\gamma$-aminobutyric acid subtype A receptor locus associated with cyclodiene insecticide resistance in Drosophila populations. Proc Natl Acad Sci USA 90:1957-1961.

Harrison JB, Chen HH, Sattelle E, Barker PJ, Huskisson NS, Rauh JJ, Bai D, Sattelle DB (1996) Immunocytochemical mapping of a C-terminus anti-peptide antibody to the GABA receptor subunit, RDL in the nervous system of Drosophila melanogaster. Cell Tissue Res 284:269-278.

Harvey RJ, Schmitt B, Hermans-Borgmeyer I, Gundelfinger ED, Betz H, Darlison MG (1994) Sequence of a Drosophila ligand-gated ion-channel polypeptide with an unusual amino-terminal extracellular domain. J Neurochem 62:2480-2483.

Hodges DD, Lee D, Preston CF, Boswell K, Hall LM, O’Dowd DK (2002) tipE regulates $\mathrm{Na}^{+}$-dependent repetitive firing in Drosophila neurons. Mol Cell Neurosci 19:402-416.

Hollrigel GS, Soltesz I (1997) Slow kinetics of miniature inhibitory postsynaptic currents during early postnatal development in granule cells of the dentate gyrus. J Neurosci 17:5119-5128.

Hosie AM, Aronstein K, Sattelle DB, ffrench-Constant RH (1997) Molecular biology of insect neuronal GABA receptors. Trends Neurosci 20:578-583.

Huntsman M, Huguenard JR (2000) Nucleus-specific differences in $\mathrm{GABA}_{\mathrm{A}}$-receptor mediated inhibition are enhanced during thalamic development. J Neurophysiol 83:350-358.

Jackson FR, Newby LM, Kulkarni SJ (1990) Drosophila GABAergic systems: sequence and expression of glutamic acid decarboxlyase. J Neurochem 54:1068-1078.

Kulkarni SJ, Newby LM, Jackson FR (1994) Drosophila GABAergic systems. II. Mutational analysis of chromosomal segment $64 \mathrm{AB}$, a region containing the glutamic acid decarboxylase gene. Mol Gen Genet 243:555-564.

Lamsa K, Palva JM, Ruusuvuori E, Kaila K, Taira T (2000) Synaptic GABA(A) activation inhibits AMPA-kainate receptor-mediated bursting in the newborn (P0-P2) rat hippocampus. J Neurophysiol 83:359-366.

Leal SM, Neckameyer WS (2002) Pharmacological evidence for GABAergic 
regulation of specific behaviors in Drosophila melanogaster. J Neurobiol 50:245-261.

Lee D, O’Dowd DK (1999) Fast excitatory synaptic transmission mediated by nicotinic acetylcholine receptors in Drosophila neurons. J Neurosci 19:5311-5321.

Lee D, O'Dowd DK (2000) cAMP-dependent plasticity at excitatory cholinergic synapses in Drosophila neurons: alterations in the memory mutant dunce. J Neurosci 20:2104-2111.

Littleton JT, Ganetzky B (2000) Ion channels and synaptic organization: analysis of the Drosophila genome. Neuron 26:35-43.

MacLeod K, Laurent G (1996) Distinct mechanisms for synchronization and temporal patterning of odor-encoding neural assemblies. Science 274:976-979.

Mody I, De Koninck YD, Otis TS, Soltesz I (1994) Bridging the cleft at GABA synapses in the brain. Trends Neurosci 17:517-525.

O'Dowd DK (1995) Voltage-gated currents and firing properties of embryonic Drosophila neurons grown in a chemically defined medium. J Neurobiol 27:113-126.

Palva JM, Lamsa K, Lauri SE, Rauvala H, Kaila K, Taira T (2000) Fast network oscillations in the newborn rat hippocampus in vitro. J Neurosci 20:1170-1178.

Restifo LL, White K (1990) Molecular and genetic approaches to neurotransmitter and neuromodulator systems in Drosophila. Adv Insect Physiol 22:115-219.

Rohrbough J, Broadie K (2002) Electrophysiological analysis of synaptic transmission in central neurons of Drosophila larvae. J Neurophysiol $88: 847-860$.
Rudolph U, Crestani F, Mohler H (2001) GABA $_{\mathrm{A}}$ receptor subtypes: dissecting their pharmacological functions. Trends Pharmacol 22:188-194.

Sattelle DB (1990) GABA receptors of insects. Adv Insect Physiol 22:1-113.

Spitzer NC, Gu X, Olson E (1994) Action potentials, calcium transients and the control of differentiation of excitable cells. Curr Opin Neurobiol 4:70-77.

Stilwell GE, Rocheleau T, ffrench-Constant RH (1995) GABA receptor minigene rescues insecticide resistant phenotypes in Drosophila. J Mol Biol 253:223-227.

Tia S, Want JF, Kotchabhakdi N, Vicini S (1996) Developmental changes of inhibitory synaptic currents in cerebellar granule neurons: role of $\mathrm{GABA}_{\mathrm{A}}$ receptor $\alpha 6$ subunit. J Neurosci 16:3630-3640.

Vicini S (1999) New perspectives in the functional role of $\mathrm{GABA}_{\mathrm{A}}$ channel heterogeneity. Mol Neurobiol 19:97-110.

Wells JE, Porter JT, Agmon A (2000) GABAergic inhibition suppresses paroxysmal network activity in the neonatal rodent hippocampus and neocortex. J Neurosci 20:8822-8830.

Wisden W, Seeburg PH (1992) $\mathrm{GABA}_{\mathrm{A}}$ receptor channels: from subunits to functinal entities. Curr Opin Neurobiol 2:263-269.

Yao WD, Rusch J, Poo M, Wu CF (2000) Spontaneous acetylcholine secretion from developing growth cones of Drosophila central neurons in culture: effects of cAMP-pathway mutations. J Neurosci 20:2626-2637.

Yusuyama K, Meinertzhagen IA, Schurmann F-W (2002) Synaptic organization of the mushroom body calyx in Drosophila melanogaster. J Comp Neurol 445:211-226.

Zhang H-G, Lee H-J, Rocheleau T, ffrench-Constant RH, Jackson MY (1995) Subunit composition determines picrotoxin and bicuculline sensitivity of Drosophila $\gamma$-aminobutyric acid receptors. Mol Pharmacol 48:835-840. 